\title{
Maternal Mortality Rates in the United States, 2020
}

\author{
by Donna L. Hoyert, Ph.D., Division of Vital Statistics
}

This report presents maternal mortality rates for 2020 based on data from the National Vital Statistics System. A maternal death is defined by the World Health Organization as, "the death of a woman while pregnant or within 42 days of termination of pregnancy, irrespective of the duration and the site of the pregnancy, from any cause related to or aggravated by the pregnancy or its management, but not from accidental or incidental causes" (1). Maternal mortality rates, which are the number of maternal deaths per 100,000 live births, are shown in this report by age group and race and Hispanic origin.

This report updates a previous one that showed maternal mortality rates for 2018 and 2019 (2). In 2020, 861 women were identified as having died of maternal causes in the United States, compared with 754 in 2019 (3). The maternal mortality rate for 2020 was 23.8 deaths per 100,000 live births compared with a rate of 20.1 in 2019 (Table).

In 2020, the maternal mortality rate for non-Hispanic Black women was 55.3 deaths per 100,000 live births, 2.9 times the rate for non-Hispanic White women (19.1) (Figure 1 and Table). Rates for non-Hispanic Black women were significantly higher than rates for non-Hispanic White and Hispanic women. The increases from 2019 to 2020 for non-Hispanic Black and Hispanic women were significant. The observed increase from 2019 to 2020 for non-Hispanic White women was not significant.

Rates increased with maternal age. Rates in 2020 were 13.8 deaths per 100,000 live births for women under age 25, 22.8 for those aged 25-39, and 107.9 for those aged 40 and over (Figure 2 and Table). The rate for women aged 40 and over was 7.8 times higher than the rate for women under age 25 . Differences in the rates between age groups were statistically significant. Among age groups, the increase in the rates between 2019 and 2020 for women aged 25-39 and 40 and over were statistically significant.

\section{Data sources and methods}

Data are from the National Vital Statistics System mortality file (4). Consistent with previous reports, the number of maternal deaths does not include all deaths occurring to pregnant or recently pregnant women, but only those deaths with the underlying cause of death assigned to International Statistical Classification of Diseases, 10th Revision code numbers A34, O00-O95, and O98-O99. Maternal mortality rates are per 100,000 live births based on data from the National Vital Statistics System natality file. Maternal mortality rates fluctuate from year to year because of the relatively small number of these events, and possibly also due to issues associated with the reporting of maternal deaths on death certificates (3). Efforts to improve data quality are continuous, and these data will continue to be evaluated for possible errors. 


\section{References}

1. World Health Organization. International statistical classification of diseases and related health problems, 10th revision. 2008 ed. 2009.

2. Hoyert DL. Maternal mortality rates in the United States, 2019. NCHS Health E-Stats. 2021. DOI: https://doi.org/10.15620/cdc:103855.

3. Hoyert DL, Miniño AM. Maternal mortality in the United States: Changes in coding, publication, and data release, 2018. National Vital Statistics Reports; vol 69 no 2. Hyattsville, MD: National Center for Health Statistics. 2020.

4. Murphy SL, Kochanek KD, Xu JQ, Arias E. Mortality in the United States, 2020. NCHS Data Brief, no 427. Hyattsville, MD: National Center for Health Statistics. 2021.

\section{Suggested citation}

Hoyert DL. Maternal mortality rates in the United States, 2020. NCHS Health E-Stats. 2022. DOI: https://dx.doi.org/10.15620/cdc:113967. 
Table. Number of live births, maternal deaths, and maternal mortality rates, by race and Hispanic origin and age: United States, 2018-2020

\begin{tabular}{|c|c|c|c|c|c|c|c|c|c|}
\hline \multirow[b]{2}{*}{$\begin{array}{l}\text { Race and Hispanic } \\
\text { origin and age }\end{array}$} & \multicolumn{3}{|c|}{2018} & \multicolumn{3}{|c|}{2019} & \multicolumn{3}{|c|}{2020} \\
\hline & Live births & $\begin{array}{c}\text { Maternal } \\
\text { deaths }\end{array}$ & $\begin{array}{l}\text { Maternal } \\
\text { mortality }\end{array}$ & Live births & $\begin{array}{l}\text { Maternal } \\
\text { deaths }\end{array}$ & $\begin{array}{l}\text { Maternal } \\
\text { mortality }\end{array}$ & Live births & $\begin{array}{l}\text { Maternal } \\
\text { deaths }\end{array}$ & $\begin{array}{l}\text { Maternal } \\
\text { mortality }\end{array}$ \\
\hline & \multicolumn{2}{|c|}{ Number } & Rate $^{1}$ & \multicolumn{2}{|c|}{ Number } & Rate $^{1}$ & \multicolumn{2}{|c|}{ Number } & Rate $^{1}$ \\
\hline Total $^{2} \ldots \ldots$ & $3,791,712$ & 658 & 17.4 & $3,747,540$ & 754 & 20.1 & $3,613,647$ & 861 & 23.8 \\
\hline Under 25 & 907,782 & 96 & 10.6 & 877,803 & 111 & 12.6 & 825,403 & 114 & 13.8 \\
\hline $25-39 \ldots \ldots$ & $2,756,974$ & 458 & 16.6 & $2,739,976$ & 544 & 19.9 & $2,658,445$ & 607 & 22.8 \\
\hline 40 and over....... & 126,956 & 104 & 81.9 & 129,761 & 98 & 75.5 & 129,799 & 140 & 107.9 \\
\hline Non-Hispanic White ${ }^{3}$. & $1,956,413$ & 291 & 14.9 & $1,915,912$ & 343 & 17.9 & $1,843,432$ & 352 & 19.1 \\
\hline Under $25 \ldots \ldots \ldots$ & 391,829 & 41 & 10.5 & 374,129 & 49 & 13.1 & 348,666 & 40 & 11.5 \\
\hline $25-39 \ldots \ldots \ldots \ldots$ & $1,504,888$ & 207 & 13.8 & $1,480,595$ & 248 & 16.8 & $1,433,839$ & 253 & 17.6 \\
\hline 40 and over....... & 59,696 & 43 & 72.0 & 61,188 & 46 & 75.2 & 60,927 & 59 & 96.8 \\
\hline Non-Hispanic Black ${ }^{3}$. & 552,029 & 206 & 37.3 & 548,075 & 241 & 44.0 & 529,811 & 293 & 55.3 \\
\hline Under $25 \ldots \ldots \ldots$ & 176,243 & 27 & 15.3 & 169,853 & 32 & 18.8 & 159,541 & 46 & 28.8 \\
\hline $25-39 \ldots \ldots \ldots$ & 358,276 & 137 & 38.2 & 360,206 & 179 & 49.7 & 351,648 & 198 & 56.3 \\
\hline 40 and over. & 17,510 & 42 & 239.9 & 18,016 & 30 & 166.5 & 18,622 & 49 & 263.1 \\
\hline Hispanic. . . . . . . . . . & 886,210 & 105 & 11.8 & 886,467 & 112 & 12.6 & 866,713 & 158 & 18.2 \\
\hline Under $25 \ldots \ldots$ & 275,553 & 21 & 7.6 & 270,948 & 23 & 8.5 & 258,635 & 20 & 7.7 \\
\hline $25-39 \ldots \ldots$ & 579,553 & 72 & 12.4 & 584,109 & 71 & 12.2 & 576,690 & 111 & 19.2 \\
\hline 40 and over. & 31,104 & 12 & * & 31,410 & 18 & * & 31,388 & 27 & 86.0 \\
\hline
\end{tabular}

* Rate does not meet National Center for Health Statistics standards of reliability.

${ }^{1}$ Maternal mortality rates are deaths per 100,000 live births.

${ }^{2}$ Total includes race and origin groups not shown separately, including women of multiple races and origin not stated.

${ }^{3}$ Race groups are single race.

NOTES: Maternal deaths are those assigned to code numbers A34, 000-095, and 098-099 of the International Classification of Diseases, 10th Revision. Maternal deaths occur while pregnant or within 42 days of being pregnant.

SOURCES: National Center for Health Statistics, National Vital Statistics System, Mortality and Natality. 
Figure 1. Maternal mortality rates, by race and Hispanic origin: United States, 2018-2020

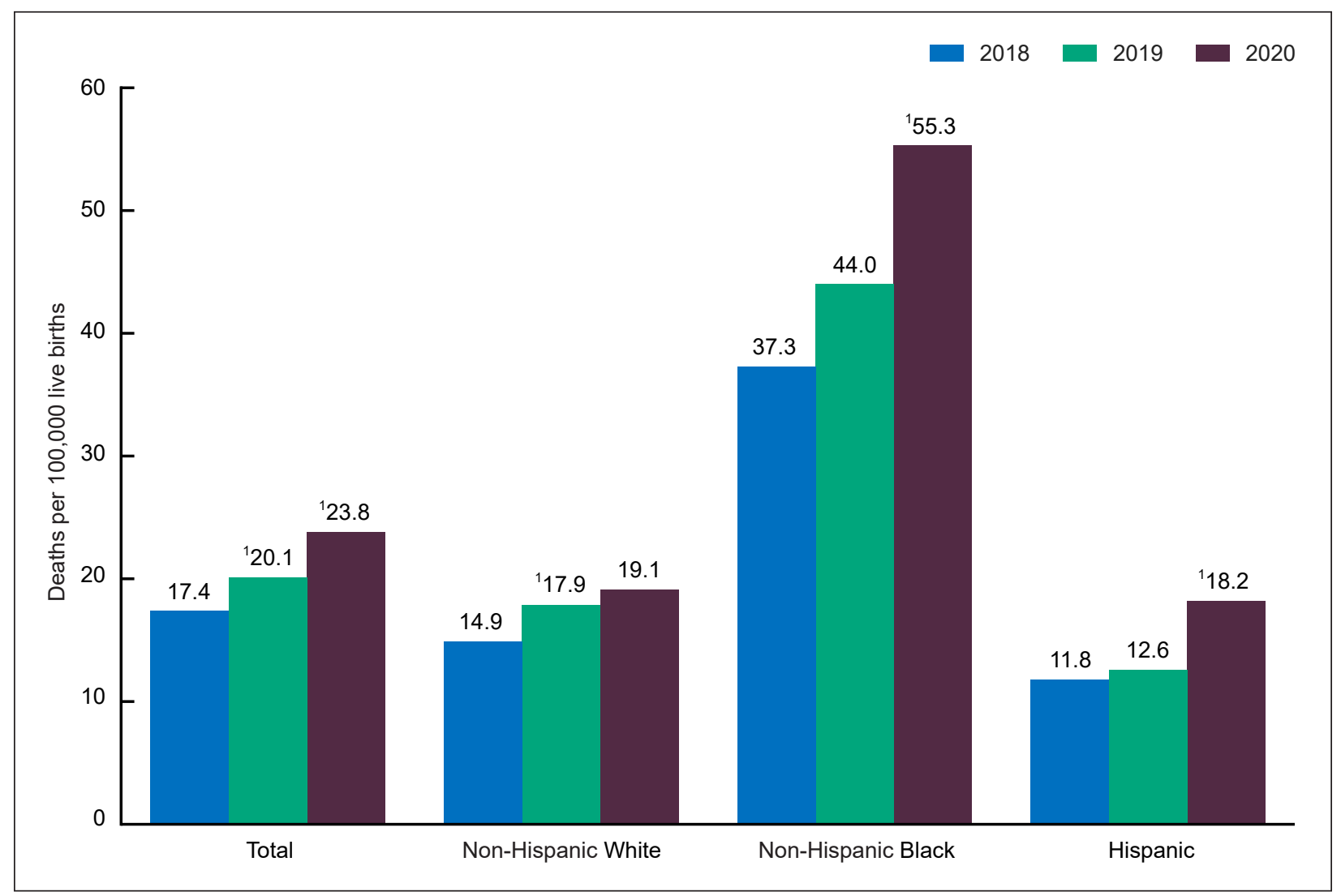

${ }^{1}$ Statistically significant increase in rate from previous year $(p<0.05)$

NOTE: Race groups are single race.

SOURCE: National Center for Health Statistics, National Vital Statistics System, Mortality. 
Figure 2. Maternal mortality rates, by age group: United States, 2018-2020

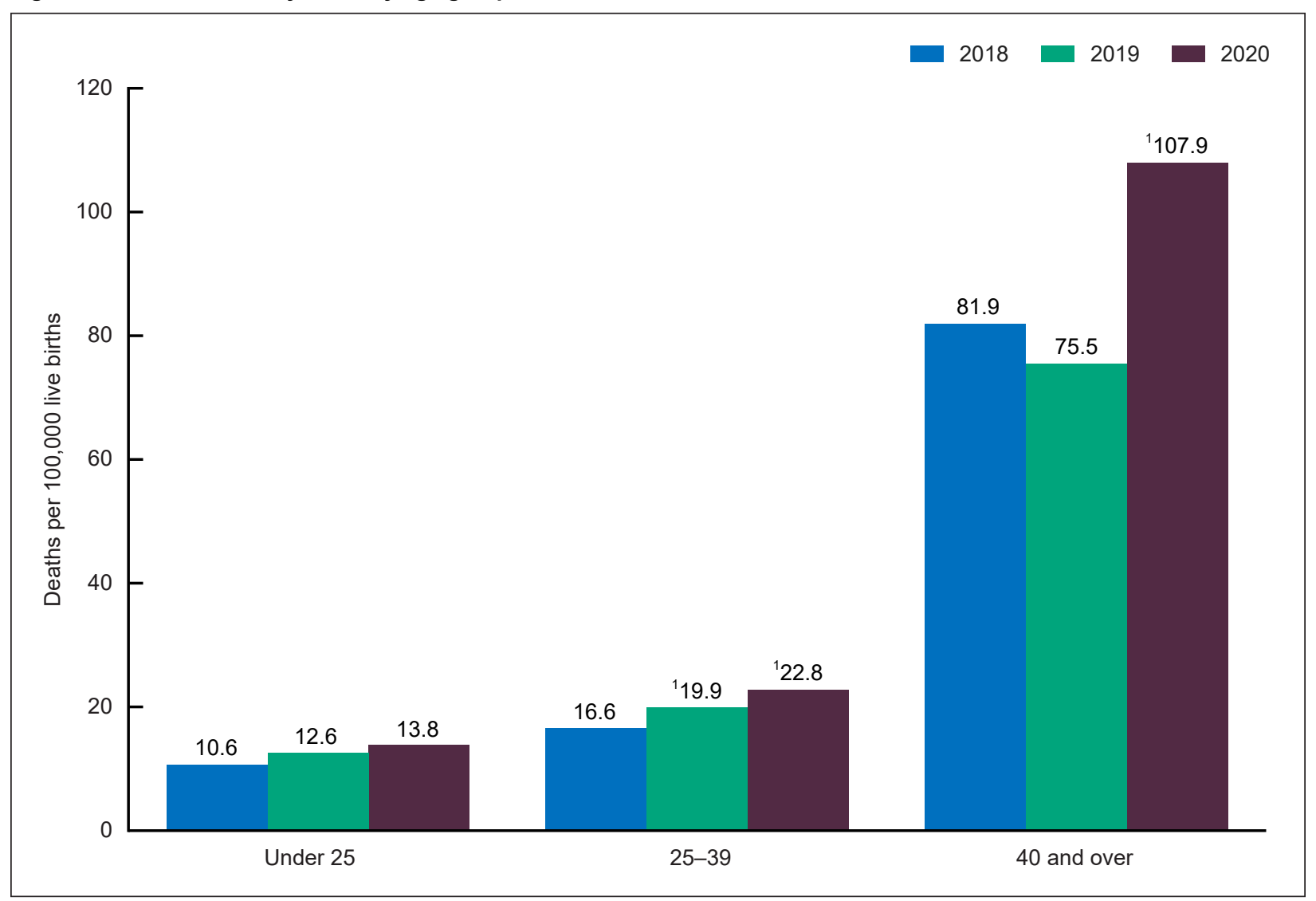

${ }^{1}$ Statistically significant increase in rate from previous year $(p<0.05)$.

SOURCE: National Center for Health Statistics, National Vital Statistics System, Mortality. 